\title{
Prevalence of various urogynaecological problems and their subsequent management with outcome amongst women attending a tertiary care hospital of a developing Country
}

\author{
Manju Arora ${ }^{1 *}$, J. B. Sharma ${ }^{2}$, Suneeta Mittal $^{3}$
}

\author{
${ }^{1}$ Department of Obstetrics and Gynecology, Kasturba Hospital, Delhi, India \\ ${ }^{2}$ Department of Obstetrics and Gynecology, All India Institute of Medical Sciences, New Delhi, India \\ ${ }^{3}$ Department of Obstetrics and Gynecology, Fortis Hospital, Gurgaon, Haryana, India
}

Received: 18 July 2017

Accepted: 18 August 2017

\section{*Correspondence:}

Dr. Manju Arora,

E-mail: aroradrmanju@gmail.com

Copyright: ( $)$ the author(s), publisher and licensee Medip Academy. This is an open-access article distributed under the terms of the Creative Commons Attribution Non-Commercial License, which permits unrestricted non-commercial use, distribution, and reproduction in any medium, provided the original work is properly cited.

\section{ABSTRACT}

Background: The prevalence of urogynaecological problems may be significantly underestimated since the physicians rarely ask women about these problems and women seldom initiate discussion about these symptoms on their own with the physician.

Methods: The present study was conducted from March 2006 to August 2008. All the women between 20 to 80 years of age with varying parity attending gynecological outpatient department were evaluated for urogynaecological and bowel problems, based on a questionnaire incorporating demographic and urogynaecological symptoms (IUGA terminology). The frequency of various urinary problems was correlated with the demographic data, urodynamic studies and cystoscopic findings, whenever appropriate and available. Exclusion criteria: The women with disorders of central nervous system, retention urine and pregnancy were excluded from the study.

Results: During this period, 15100 women attended outpatient department of gynecology. Out of these, 376 women had urogynaecological and bowel problems. The prevalence of urogynaecological and bowel problems was 24.9 per 1000 women. The incidence of symptoms was dysuria in $38.5 \%$ women, increased frequency of micturition in $38 \%$ women; feeling of something coming out per vaginum in $37 \%$ women, nocturia in $27.6 \%$ women and pain lower abdomen in $25 \%$ women.

Conclusions: Amongst incontinence, 31.3\% women had stress incontinence, $25 \%$ women had urge incontinence, $14.6 \%$ women had urgency, $8.7 \%$ women had continuous urinary incontinence and $2.12 \%$ women had anal incontinence.

Keywords: Prevalence, Urogynaecological problems, Women

\section{INTRODUCTION}

The prevalence of uro-gynecological problems may be significantly underestimated since the physicians rarely ask women about these problems and the women seldom initiate discussion on their own about them with the physician. The older women may assume that urinary incontinence is a normal consequence of ageing. Some women do not disclose their problems because of fear of invasive testing or because of perceived stigma of symptoms. The inability to control urine is most unpleasant and distressing problem. Although it is not life threatening, it causes substantial debility, social seclusion, psychological stress and economical burden. 
The involuntary loss of urine is not a normal part of ageing. It often becomes a clinical problem for the ageing women due to the trauma of child birth, development of acute and chronic illness, loss of estrogenic stimulation at menopause, weaker pelvic support and diminished amount of normal homeostatic reserve available to cope with stresses placed on the bladder.

The pelvic organ prolapse is a symptom arising from pelvic floor dysfunction. Other common symptoms are stress and urge incontinence, sexual dysfunction and fecal incontinence, which are often found in various combinations. The most prevalent symptoms of urinary Incontinence, fecal incontinence and pelvic organ prolapse affect women three to seven times more often than men.

The voiding dysfunction in the elderly is the most common gerontolgic problem, occurring more frequently than cardiovascular disorders or rheumatoid arthritis. It is due to the failure of detrussor contraction. It has far reaching medical, psychological and socio-economic implications.

\section{METHODS}

This prospective clinical study was undertaken among the women between the age group of 20 to 80 years attending outpatient department of Gynecology, with approval of the ethics committee of the institute and after obtaining written informed consent. The present study was conducted from March 2006 to August 2008. A total of 15100 women attended gynecological outpatient department.
Women with disorders of the central nervous system, retention urine and pregnancy were excluded from the study. A questionnaire was developed in which various signs and symptoms of genital prolapse, urinary symptoms and bowel symptoms were incorporated. It comprised of questions in four domains concerning previous obstetrical history, mechanical symptoms, lower urinary tract symptoms (LUTS) including those dealing with stress incontinence and bowel symptoms. We adopted the questionnaire developed by Kelleher et al from Kings College Hospital London to develop the present questionnaire (as shown in Appendix) suiting our requisites. ${ }^{1-6}$ It included demographic data of women like age, marital status, education, smoking, degree of physical stress, menopausal status, obstetrical history in terms of parity, mode of delivery, whether forceps or ventouse application or prolonged second stage of labour, baby's birth weight, performance and duration of postnatal exercises. The previous history of any surgery like caesarean section, hysterectomy, surgery for repair of genital prolapse, the incontinence surgery and fistula repair was noted. The medical history of any chronic illness like diabetes mellitus, hypertension, hypothyroidism or any neurological disorder was also noted.

The symptoms were then re-corroborated as per the current definitions issued by the International Continence Society (ICS) Joint Report and the terminology for the female pelvic floor dysfunction and the standard textbooks as these definitions came after the study was over. ${ }^{7-10} \mathrm{We}$ used to extract information regarding various urogynaecological symptoms like dysuria, nocturia etc. as tabulated in Table 1.

Table 1: Definition of symptoms.

\begin{tabular}{|c|c|}
\hline Symptom & Definition \\
\hline Increased daytime frequency & Complaint by the woman who considers that she voids too often by day \\
\hline Dysuria & Complaint of burning or other discomfort during micturition \\
\hline Vaginal bulging & $\begin{array}{l}\text { Complaint of a "bulge" or "something coming down "towards or through the } \\
\text { vaginal introitus }\end{array}$ \\
\hline Urgency & Sudden and compelling desire to pass urine, which is difficult to defer. \\
\hline Urge Urinary Incontinence & Complaint of involuntary loss of urine associated with urgency. \\
\hline Stress Urinary Incontinence & Complaint of involuntary loss of urine on effort or physical exertion. \\
\hline Mixed urinary incontinence & $\begin{array}{l}\text { Both of them-complaint of involuntary leakage associated with urgency and also } \\
\text { with exertion, effort, sneezing or coughing. }\end{array}$ \\
\hline Nocturia & Rising from sleep to void at night \\
\hline Continuous urinary incontinence & Complaint of continuous leakage \\
\hline Hesitancy & Complaint of a delay in initiating micturition \\
\hline Urinary tract infection & Presence of more than 100000 organisms per ml of urine (significant bacteriuria) \\
\hline Anal incontinence & Complaint of involuntary loss of feces or flatus. \\
\hline Haematuria & Presence of blood in the urine \\
\hline Nocturnal enuresis & Complaint of loss of urine occurring during sleep \\
\hline
\end{tabular}


The frequency of various urogynaecological and bowel problems was correlated with demographic data, urodynamic studies and cystoscopic findings whenever appropriate and available.

Thorough clinical examination of the women was done with assessment of age, weight, height, blood pressure as well as abdomino-pelvic examination to note pathology like uterine prolapse, rectocele, enterocele, bulbocavernosus reflex, anal sphincter tone and vaginal atrophy. In all the women with incontinence, cough stress test, pad test, urine analysis and ultrasonography to note post residual volume were done. In women with vesicovaginal fistula, the detailed examinations included per speculum examination, catheter test, dye test, three swab test and the examination under anesthesia to assess the location and size of fistula. Complete urine analysis, cystoscopy and intravenous pyelography was done in each woman prior to surgery.

Any urinary tract infection was treated with appropriate antibiotics and was reassessed after treatment for surgery. All women were encouraged to increase fluid intake, to decrease caffeine intake and given dietary advice, if they were overweight. Atrophic vaginitis was treated with Dienoesterol vaginal cream $(0.01 \%)$. The information on incontinence pads and pants was provided.

The women with urge incontinence were asked to keep a diary of the number of times urine voided and number of episodes of incontinence over one week. A programme of bladder training was commenced, where women were encouraged to void at regular intervals, increasing from hourly, to one and a half hourly, two hourly, up to three or four hourly. If there was no improvement in two weeks and voiding was hourly by day or two hourly by night, the women were started on anti-muscarinic drug, Terodine $12.5 \mathrm{mg}$ twice a day increasing the dose upto a maximum of $75 \mathrm{mg}$ per day for three months until a response was obtained or the side effects experienced.

The women with stress urinary incontinence (confirmed on urodynamic studies) were offered initially pelvic floor exercises (PFE) for seven weeks, failing which they were offered the surgical treatment, depending on the severity and associated diagnosis. In women with genital prolapse, Kelly's repair or Obturator tape along with vaginal hysterectomy was done. Alternatively, the women with pure stress urinary incontinence had Burch's colposuspension or obturator tape or Trans vaginal tape (TVT). The women with mixed incontinence were treated for both stress and urge incontinence.

\section{RESULTS}

Out of 15100 women, 376 women had one or the other urinary or bowel problem. Thus, the prevalence of urogynecological problems was 24.9 per 1000 women.

Table 2: Incidence of symptoms.

\begin{tabular}{|lll|}
\hline Symptom & No. of Women & $\%$ \\
\hline Dysuria & 145 & 38.5 \\
\hline Increased daytime urinary frequency & 143 & 38 \\
\hline Vaginal bulging (feeling of something coming out per vaginum) & 142 & 37.7 \\
\hline Stress urinary incontinence & 118 & 31.3 \\
\hline Nocturia & 103 & 27.6 \\
\hline Urge urinary incontinence & 94 & 25 \\
\hline Pain lower abdomen & 94 & 25 \\
\hline Urgency & 55 & 14.6 \\
\hline Continuous urinary incontinence & 33 & 8.7 \\
\hline Passage of stools per vaginum & 8 & 2.12 \\
\hline
\end{tabular}

Table 3: Diagnosis.

\begin{tabular}{|lll|}
\hline Diagnosis & No. of women & $\%$ \\
\hline Urinary tract infection & 130 & 34.5 \\
\hline Genital prolapse & 126 & 33.5 \\
\hline Urge urinary incontinence & 51 & 13.5 \\
\hline Vesico-vaginal fistula & 33 & 8.7 \\
\hline Stress urinary incontinence & 28 & 7.4 \\
\hline Mixed urinary incontinence & 27 & 7.18 \\
\hline Complete perineal tear & 6 & 1.5 \\
\hline Recto-vaginal fistula & 2 & 0.5 \\
\hline
\end{tabular}


Most women were in the range of 20 to 60 years. Two hundred sixty-nine women out of $376(71.5 \%)$ were para. $^{2-4}$ Out of 376 women, 145 women $(38.5 \%)$ had dysuria, 143 women (38\%) had increased day time urinary frequency, 142 women $(37.7 \%)$ had feeling of something coming down and 118 women (31.3\%) had stress urinary incontinence as shown in Table 2.

One hundred thirty women $(34.5 \%)$ were diagnosed to have urinary tract infections, 126 women $(33.5 \%)$ had genital prolapse and 51 women (13.5\%) had urge incontinence as shown in Table 3.

One hundred and nine women $(28.9 \%)$ had medical management in the form of antibiotics, 23 women $(6.1 \%)$ were given Tolterodine for urge incontinence and 16 women $(4.2 \%)$ were treated with Duloxetine for stress urinary incontinence as shown in Table 4.

Table 4: Medical management.

\begin{tabular}{|lll|}
\hline Drug & No. of women & $\%$ \\
\hline Antibiotics & 109 & 28.9 \\
\hline Tolterodine & 23 & 6.1 \\
\hline Duloxetine & 16 & 4.2 \\
\hline Anti-tubercular treatment & 4 & 1.06 \\
\hline Hormone replacement therapy & 1 & 0.2 \\
\hline
\end{tabular}

Table 5: Surgical management.

\begin{tabular}{|c|c|c|}
\hline Surgery & $\begin{array}{l}\text { No. of } \\
\text { women }\end{array}$ & $\%$ \\
\hline $\begin{array}{l}\text { Vaginal hysterectomy with pelvic } \\
\text { floor repair }\end{array}$ & 76 & 20.2 \\
\hline Repair of vesico-vaginal fistula & 11 & 2.9 \\
\hline Laproscopic sacro-colpopexy & 10 & 2 \\
\hline Fothergill's repair & 9 & 2.3 \\
\hline Transvaginal tape application & 8 & 2.1 \\
\hline Anterior collpo-perineorrhaphy & 3 & 0.7 \\
\hline Complete perineal tear repair & 3 & 0.7 \\
\hline Total abdominal hysterectomy & 3 & 0.7 \\
\hline $\begin{array}{l}\text { Vaginal hysterectomy with pelvic } \\
\text { floor repair with Kelly's operation }\end{array}$ & 2 & 0.5 \\
\hline Abdominal sling surgery & 1 & 0.2 \\
\hline Burch colpo suspension & 1 & 0.2 \\
\hline $\begin{array}{l}\text { Total abdominal hysterectomy with } \\
\text { cervico-vaginal fistula repair with } \\
\text { ureteral implantation }\end{array}$ & 1 & 0.2 \\
\hline $\begin{array}{l}\text { Total abdominal hysterectomy with } \\
\text { cystostomy with vaginoplasty }\end{array}$ & 1 & 0.2 \\
\hline Insertion of ring pessary & 1 & 0.2 \\
\hline $\begin{array}{l}\text { Ureteral implantation into urinary } \\
\text { bladder }\end{array}$ & 1 & 0.2 \\
\hline
\end{tabular}

The surgical management was done in 143 women (38\%). Seventy-six women (20.2\%) had vaginal hysterectomy with pelvic floor repair, 11 women $(2.9 \%)$ had repair of vesico-vaginal fistula, 10 women $(2.6 \%)$ had laproscopic sacro-colpopexy for vault prolapse, while
8 women $(2.1 \%)$ had trans vaginal tape application (TVT) for stress urinary incontinence (SUI) as shown in Table 5 .

During investigations, four women $(1 \%)$ were found to have tuberculosis. Three women had urinary tract tuberculosis diagnosed by DNA-PCR test, while one of the women was diagnosed by chest skiagram.

\section{DISCUSSION}

The pelvic organ prolapse is a symptom arising from pelvic floor dysfunction. Other common symptoms are stress and urge incontinence, sexual dysfunction and fecal incontinence, which are often found in various combinations. Incontinence is a condition that causes a great deal of distress and occurs mainly among women. The women find it difficult to talk about urinary and anal incontinence. Anal incontinence is a distressing and disabling condition causing significant morbidity predominantly in women. Vaginal delivery appears to be main cause of anal incontinence. Inoue $\mathrm{H}$ et al, in fact reported that the slow birth, the duration of second stage exceeding 4 hours, may protect the pelvic floor against injury due to delivery. ${ }^{11}$

Briger et al reported the prevalence of urinary dysfunction in $13 \%$ of women. ${ }^{12}$ Stress incontinence was in $21 \%$ of respondents, urgency or urge incontinence in $11.5 \%$, urinary frequency in $19 \%$, nocturia in $20 \%$, bedwetting in $4 \%$ and voiding difficulties in $13 \%$. Stress incontinence occurred as the only symptom in $7 \%$, the combination of urge and frequency in $1 \%$ and mixed symptoms in $6 \%$. Symptoms of urge, urge incontinence, frequency and nocturia increased with increasing age, but voiding difficulties and nocturnal enuresis were unrelated to the age. ${ }^{13}$ These urinary dysfunctions increased with increasing parity.

In present study, $38.5 \%$ women had dysuria, $38 \%$ women had increased frequency of micturition, $35 \%$ women complained of vaginal bulge, $31.3 \%$ women had stress urinary incontinence, $27.6 \%$ women had nocturia, $25 \%$ women had urge incontinence, $14.6 \%$ women had urgency, $8.6 \%$ women had continuous urinary incontinence and $2.12 \%$ women had passage of stools per vaginum.

Zhang et al reported that menopause, parity more than two, constipation, fetal birth weight and episiotomy were common potent risk factors for these urogynaecological problems. ${ }^{14}$ Higher body mass index (BMI) and ageing increase the occurrence of lower urinary tract symptoms (LUTS) and storage symptoms. While cesarean delivery can protect against these symptoms, as it can avoid damage to the pelvic floor musculature or to the pudendal nerve. Episiotomy may cause damage to the uretheral and bladder supportive structures or to the pelvic nerve plexus. Similarly, parous or women with higher fetal birth weight may have these symptoms many years after 
delivery because of damage to the pelvic floor musculature or to the pudendal nerve during childbirth. Excess body weight and constipation may increase the abdominal pressure during physical activity or defecation, which in turn increases bladder and urethral mobility, leading to lower urinary tract symptoms (LUTS).

We also found that older age, increasing parity, menopause and episiotomy as risk factors for urogynaecological problems. About $40.6 \%$ women were given medical management in the form of antibiotics, antitubercular treatment, Tolterodine, Duloxetine and hormone replacement therapy. The surgical management was done in $38 \%$ women. Although many studies on the prevalence of urogynaecological problems have been published from developed countries, the studies from developing countries have been sparse. ${ }^{15}$

\section{CONCLUSION}

Our study confirms the high prevalence of urogynaecological problems among women in India with the prevalence being more common in elderly, obese, multiparous and post-menopausal women. The women usually consider these urogynaecological problems as normal part of ageing or feel shameful or hesitant to express. The impact on the quality of life is the major reason for these women to seek medical help.

\section{Funding: No funding sources}

Conflict of interest: None declared

Ethical approval: The study was approved by the Institutional Ethics Committee

\section{REFERENCES}

1. Kelleher CJ, Cardozo LD, Khullar V, Salvatore S. A new questionnaire to assess the quality of life of urinary incontinent women. Br J Obstet Gynaecol. 1997;14(12):1374-9.

2. Sharma JB, Malhotra M, Gupta S, Kumar A, Singh B $\mathrm{P}$, Vindal A. A preliminary survey of women views on awareness, information choices and expectations in women undergoing hysterectomy. J Indian Med Assoc. 2004;102:304-8.

3. Sharma JB, Malhotra M, Joshi D, Arora R. Survey of the women views on awareness, information, choices and care during labour in a teaching hospital Obstet Gynecol India. 2003;53:252-6.

4. Sharma JB, Sharma K, Sarin U.A study of maternal awareness and participation during cesarean section. J Obstet Gynecol India. 2001;51:37-9.
5. Sharma JB, Gupta N, Aggarwal P, Mittal S. A survey of obstetrician's practice of using prophylactic antibiotics in vaginal deliveries and cesarean sections. J Indian Med Assoc. 2008:106:147-9.

6. Sharma JB, Wadhwa L, Mittal S. Survey of knowledge, attitude and practices of urogynaecological problems amongst gynaecologists of Delhi. Indian J Med Sci. 2005:59;28-30.

7. Hayln BT, de Ridder D, Freeman RM, et al. An International Urogynecological Association (IUGA)/International Continence Society (ICS) joint report on the terminology for female pelvic floor dysfunction. Int Urogynecol J. 2010;21(1):5-26.

8. Bass M, Duckett JRA. Management of the overactive bladder syndrome. In: Studd J, tan SL chervenek FA(eds), progress in Obstetrics and Gynecology. 2008;18:365-78.

9. Rufford J. Urinary Incontinence. In: Luesley DM, Baker PN (eds): Obstetrics and Gynaecology. An evidence based text for MRCOG. $1^{\text {st }}$ edn. Arnold London; 2004;634-48.

10. Balmforth J. Assessment of lower urinary tract function. In: Leusley D M, Baker PN (edsObstetrics and Gynecology. An evidence based text for MRCOG. Men Arnold. London. 2004;619-33.

11. Inove H, Sekiguchi Y. Does the slowbirth protects the pelvic floor against injury due to delivery? Int Urogynecol J. 2003;77(268):S23.

12. Brieger GM, Yip SK, Hin ly, Chung TKh. The prevalence of urinary dysfunction in Hong Kong Chinese women. Obstet Gynecol. 1996:88(6):10414.

13. Swithinbark LV, Donvan JL, Haone JC. Urinary symptoms and incontinence in women; relationship between occurrence, age and perceived impact. $\mathrm{Br} \mathrm{J}$ Gen Pract. 1999;49;897-900.

14. Zhang W, Song Y, He X, Li BY. European urology prevalence and risk factors of lower urinary tract symptoms in Funzhou Chinese women. 2005;48:309-13.

15. Hanif S. Frequency and pattern of Urinary complaints among pregnant women. J Coll Physician Surg Pak. 2006;16:514-7.

Cite this article as: Arora M, Sharma JB, Mittal S. Prevalence of various urogynaecological problems and their subsequent management with outcome amongst women attending a tertiary care hospital of a developing Country. Int J Reprod Contracept Obstet Gynecol 2017;6:4407-12. 


\section{ANNEXURE}

Questionnaire for prevalence of urogynecological problems in women.

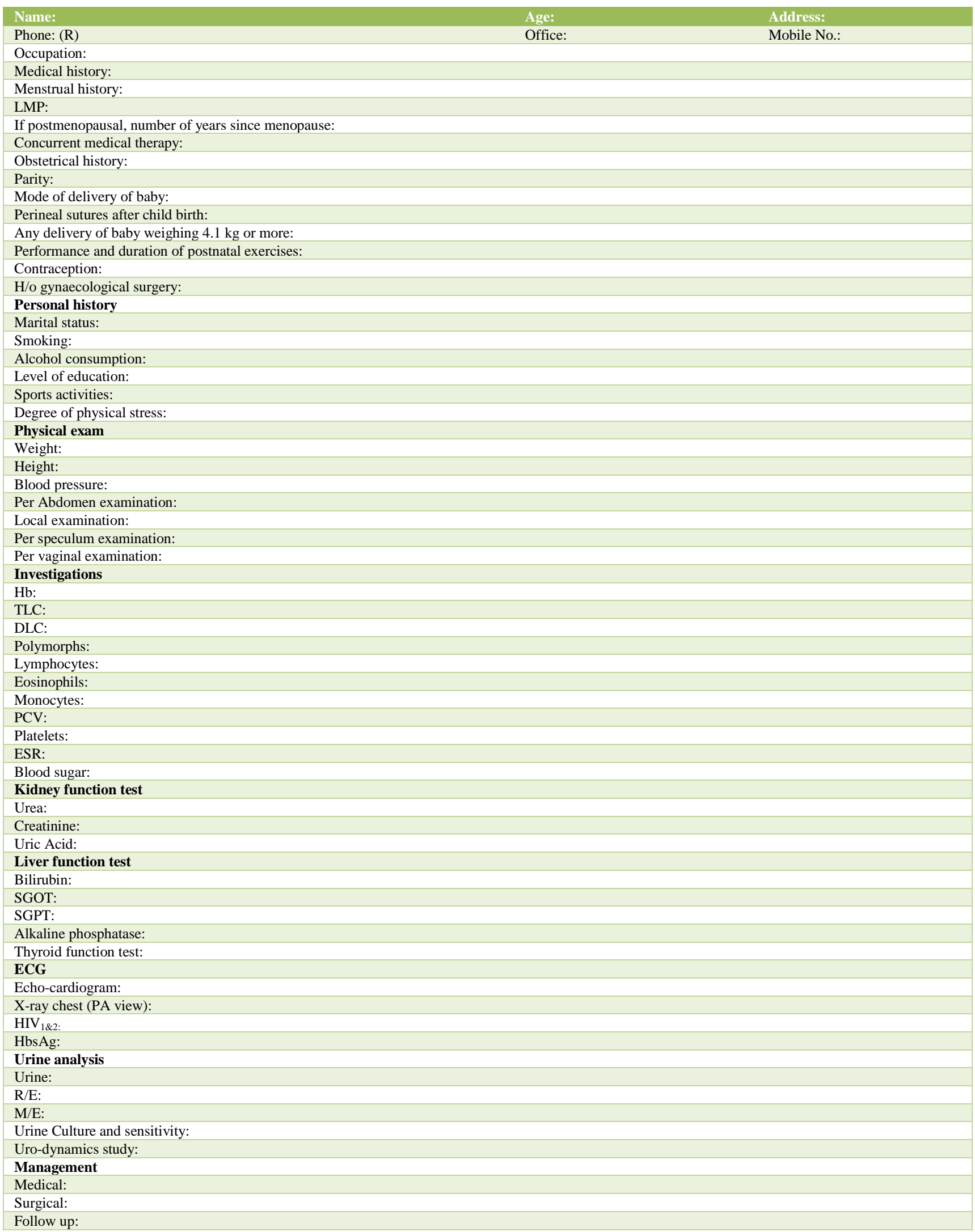

